\title{
Assessment of the risk of cyanobacterial bloom occurrence in urban ponds: probabilistic approach
}

\author{
Anatoly Peretyatko*, Samuel Teissier, Sylvia De Backer and Ludwig Triest \\ Plant Science and Nature Management, Department of Biology, Vrije Universiteit Brussel, Pleinlaan 2, 1050 Brussels, Belgium
}

Received 7 November 2009; Accepted 23 February 2010

\begin{abstract}
Blooms of toxic cyanobacteria became a common feature of temperate lakes and ponds owing to human induced eutrophication. Occurrence of cyanobacterial blooms in an urban context may pose serious health concerns. This necessitates the development of tools for assessment of the risk of noxious bloom occurrence. A five year study of 42 Brussels ponds showed that cyanobacteria have threshold rather than linear relationships with environmental variables controlling them. Hence, linear relationships have limited predictive capacity for cyanobacterial blooms. A probabilistic approach to prediction of bloom occurrence using environmental thresholds as conditions in conditional probability calculation proved to be more useful. It permitted the risk of cyanobacterial bloom occurrence to be quantified and thus the conditions and thence the ponds the most prone to cyanobacterial bloom development to be singled out. This approach can be applied for the assessment of the risk of cyanobacterial bloom occurrence in urban ponds and thus can facilitate monitoring planning, remediation efforts and setting restoration priorities.
\end{abstract}

Key words: Cyanobacteria / eutrophication / threshold relationship / conditional probability

\section{Introduction}

Constant human population growth puts ever-growing pressure on the environment that is reflected on the ecological integrity of aquatic ecosystems. Human induced changes in the global nutrient cycles caused a dramatic increase in frequency, magnitude and duration of harmful phytoplankton blooms during the past decades (Graham and Wilcox, 2000; Hudnell, 2008). Such blooms may cause fish kills through anoxia and toxins, have adverse health effects on humans and domestic animals and contribute to the loss of biodiversity in aquatic ecosystems (Graham and Wilcox, 2000; Carmichael, 2001; Briand et al., 2003; Pflugmacher, 2004). There are indications of ecological water quality degradation often resulting in the formation of potentially toxic cyanobacterial blooms in many countries including Belgium (Jeppesen et al., 1997; Sanchis et al., 2002; Willame et al., 2005; Peretyatko, 2006; Carmichael, 2008). Therefore understanding of the causes and identification of the main factors controlling noxious blooms become increasingly important, particularly in the urban context where many ponds are used for different recreational activities. Better understanding would allow prediction of bloom occurrence and,

\footnotetext{
*Corresponding author: Anatoly.Peretyatko@vub.ac. be
}

subsequently, more focused planning of management interventions.

A number of factors are known to exert a strong influence on cyanobacteria. As active net production of each component of the plankton is primarily regulated by its consumers (Reynolds, 2006), large Cladocera grazing is often evoked as an important factor in cyanobacterial blooms control (Sarnelle, 1992; Christoffersen et al., 1993; Matveev et al., 1994; Agrawal, 1998; Oberhaus et al., 2007). There are a number of studies, however, that question the efficiency of large cladocerans to control cyanobacteria owing to the anti-grazing adaptations of the latter (Gliwicz, 1990; Gliwicz and Lampert, 1990; DeMott et al., 2001). Some investigators go as far as categorizing bloom-forming cyanobacteria as inedible by zooplankton (e.g. Benndorf et al., 2002).

Beside adaptations against zooplankton grazing, many cyanobacteria are capable of fixing atmospheric nitrogen, which makes them more competitive than other phytoplankters in nitrogen limiting conditions (Graham and Wilcox, 2000; Reynolds, 2006). Cyanobacteria have also proven to be more efficient than other algae in tackling the problem of carbon deficiency and, therefore, are favored by elevated $\mathrm{pH}$ conditions characterized by low $\mathrm{CO}_{2}$ concentrations in the water (Shapiro, 1973, 1997). They have also developed efficient mechanisms of light 
harvesting and buoyancy regulation. Individual species of cyanobacteria do not seem to be adapted to a full range of environmental variability, they rather selectively exploit different parts of the wide range of environmental conditions. This accounts for their ecological success as a group (Reynolds, 2006).

The cost of the numerous adaptations developed by cyanobacteria is often a slower rate of growth than that of many other algae (Agrawal, 1998; Reynolds, 2006), which gives the latter a competitive advantage, particularly in smaller water bodies characterized by high flushing rates.

Submerged plants are known to be able to inhibit growth of phytoplankton in general and cyanobacteria in particular through a number of associated mechanisms such as changes in nutrient cycling, allelopathy, shading, increased sedimentation and grazing (Søndergaard and Moss, 1998; Van Donk and Van De Bund, 2002; Peretyatko et al., 2007a). Submerged plants play a greater role in shallower ponds and lakes with an extended littoral zone, and exert a minor effect, if any, on phytoplankton in deeper water bodies (Scheffer, 1998; Jones et al., 2002).

Another factor that can select against cyanobacteria is a greater depth. A number of studies have shown that some bloom-forming cyanobacteria are poorly adapted to water column mixing (Reynolds et al., 1987; Huisman et al., 1999; Jacquet et al., 2005) and therefore are less likely to develop persistent blooms in well mixed deeper lakes and ponds.

Although cyanobacteria have been extensively studied, most of the studies were focused on the effects of individual factors (e.g. zooplankton grazing, $\mathrm{pH}$, mixing) or were limited to a small number of lakes or ponds. Studies of a large number of water bodies aiming at assessing the individual as well as the combined effect of different environmental factors on cyanobacteria are few (e.g. Downing et al., 2001).

Based on the data from 42 contrasting urban ponds sampled on 381 occasions between the years 2003-2007 for phytoplankton, zooplankton, submerged vegetation and a number of environmental variables, the objective here was to identify the main factors controlling cyanobacteria with the aim of developing a model for predicting cyanobacterial bloom occurrence. The contrasting ecology of the ponds studied was used to select subsets of samples from ponds controlled by different factors. Since phytoplankton community composition depends to a considerable degree on chance (Reynolds, 2006), a probabilistic approach was used for comparisons of the effects of different factors and their combinations on cyanobacteria.

\section{Methods}

Forty-two ponds from the Brussels Capital Region, Belgium, have been studied during the period of 2003-2007. The ponds are all artificial, created by the damming of small low order streams in the 20th century or earlier. The ponds are shallow (maximum depth $<3.5 \mathrm{~m}$ ) and flat-bottomed. They range in surface area from 0.15 to 6 ha. Some ponds are connected to different stream systems, while others are mainly fed by ephemeral rivulets and ground water seepage. A number of ponds are used for different recreational activities, with fishing and boating being the most common. The ponds are populated by fish communities typical of northern Europe (mainly carp, crucian carp, roach, bream, tench, perch, pikeperch and pike). Many ponds are overstocked with fish $\left(>600 \mathrm{~kg} \cdot \mathrm{ha}^{-1}\right)$.

Different subsets of 42 Brussels ponds have been sampled 3 to 21 times during the warm months (MaySeptember) of the study period. This makes up 381 samplings (Appendix 1 available online at www.limnologyjournal.org) of phytoplankton, zooplankton, main nutrients (total phosphorus - TP, soluble reactive phosphorus - SRP, $\mathrm{NO}_{3}, \mathrm{NO}_{2}, \mathrm{NH}_{4}$ and $\mathrm{SiO}_{2}$ ), chlorophyll $a$ $(\mathrm{Chl} a)$ as well as measurements of conductivity, $\mathrm{pH}$, temperature, and water transparency (Secchi depth) that were done according to the standard limnological procedures. Mixed water samples of $10 \mathrm{~L}$ based on 10 random sub-samples of $1 \mathrm{~L}$ were taken from each pond with a plastic tube sampler of $4.5 \mathrm{~cm}$ diameter and $70 \mathrm{~cm}$ length that closes in the lower part. A special extension was fixed to the sampler to reach the deeper parts of the ponds when appropriate. Water samples preserved with Lugol's solution, sodium thiosulfate and buffered formalin (Kemp et al., 1993) were used for phytoplankton identification (genus level) and counting with an inverted microscope (a modified Utermöhl sedimentation technique; Hasle, 1978). Biovolumes were calculated using the approximations of cell shapes to simple geometrical forms (Wetzel and Likens, 1990). For zooplankton, 10 random subsamples of $1 \mathrm{~L}$ were taken with the same sampler as used for phytoplankton sampling, combined in the field, filtered through a $64 \mu \mathrm{m}$ mesh net and preserved in $4 \%$ formaldehyde final concentration before being identified and counted using an inverted microscope. Different levels of identification were used: cladocerans were identified to genus level; copepods were divided into cyclopoids, calanoids and nauplii; rotifers were not discriminated. For the analyses, cladocerans were divided into two groups: 'large' (Daphnia spp., Eurycercus spp., Sida spp. and Simocephalus spp.) and 'small' (Acroperus spp., Bosmina spp., Ceriodaphnia spp., Chydorus spp., Moina spp. and Pleuroxus spp.) (Moss et al., 2003). Predator cladocerans, Leptodora spp. and Polyphemus spp., that feed mainly on other zooplankters (Reynolds, 2006), were not included in the group of large cladocerans. The length of large Cladocera species was measured in 2005-2007 and taken as an indicator of grazing intensity and size-selective predation (Pourriot, 1995; Carpenter et al., 2001). Surface cover of aquatic vegetation was mapped visually from a boat during each field visit. Morphometric variables of the ponds were measured in the field (depth), or using GIS software (area; digitized map, ArcView 3.2). Hydraulic retention time was estimated on the basis of the outlet discharge and the corresponding pond volume once a year in 2003-2006 and monthly in 2007. 
Table 1. Main genera of bloom-forming cyanobacteria and the ponds where they occurred during the study period.

\begin{tabular}{|c|c|c|c|c|c|c|c|}
\hline & Anabaena & Anabaenopsis & Aphanizomenon & Limnothrix & Microcystis & Planktothrix & Woronichinia \\
\hline$\overline{\text { Hrt1 }}$ & + & & & & + & & \\
\hline Hrt2 & + & & & & & & \\
\hline IxP1 & & & + & + & + & + & \\
\hline IxP2 & + & + & + & + & + & + & + \\
\hline Leyb-a & + & + & + & + & + & + & \\
\hline Leyb-b & + & + & + & + & & + & \\
\hline $\mathrm{MlGr}$ & + & & + & & + & + & \\
\hline MlK1 & + & + & + & + & + & + & \\
\hline $\mathrm{NrPd}$ & + & & + & & + & + & \\
\hline RK13 & + & & + & & & + & \\
\hline $\mathrm{TrBr}$ & + & & + & & + & + & \\
\hline WPk1 & & & + & & + & + & \\
\hline WPk2 & + & & + & & + & + & \\
\hline
\end{tabular}

Standard multivariate and univariate statistical tests were used to assess the relationships between cyanobacteria and environmental factors. Because the gradient length was below 1.7 standard deviations, showing poor unimodality, a linear method, redundancy analysis (RDA; ter Braak and Smilauer, 2002), based on averaged per year phytoplankton and environment data was used to elucidate relationships between phytoplankton and environmental factors operating in the ponds studied. Phytoplankton data were aggregated to division level in order to estimate the relationships between environmental factors and different phytoplankton groups. Only 2005-2007 data (276 sampling occasions) were used in the RDA because the environmental dataset for these years was the most complete.

For the reason of the limited predictive capacity of linear relationships, the factors showing threshold relationships with cyanobacteria were used to assess the likelihood of cyanobacterial bloom occurrence in different environmental conditions. Threshold values were identified using scatter plots showing the relationships between cyanobacteria and environmental factors and fixed at the level corresponding to maximum probability values and minimal loss of cyanobacterial bloom cases. These thresholds were applied as conditions in the calculation of conditional probabilities of cyanobacterial bloom occurrence (i.e. probability of cyanobacterial bloom occurrence at the condition that a given environmental factor or a combination of factors is above/below the threshold/ thresholds). The probability values thus obtained were considered as a measure of predictive capacity and were used to compare the risk of bloom occurrence at different environmental conditions and in different ponds. The cyanobacterial biovolumes in excess of $5 \mathrm{~mm}^{3} \cdot \mathrm{L}^{-1}$ were arbitrarily chosen as indicators of the cyanobacterial bloom occurrence. Details of these analyses and probability calculation are given in the Results section.

\section{Results}

All the ponds studied were characterized by high nutrient levels. TP concentrations were on average above
$0.1 \mathrm{mg} . \mathrm{L}^{-1}$ (Appendix 2 available online at www.limnology-journal.org). Dissolved inorganic nitrogen concentrations varied a lot from pond to pond and, although mostly substantially lower than in some other European ponds and small lakes (Cottenie et al., 2001; Irfanullah and Moss, 2005; Moss et al., 2005; Søndergaard et al., 2005), they generally exceeded the level at which phytoplankton growth could be slowed down due to nitrogen limitation (Appendix 2; Reynolds, 2006). High productivity potential was realised in some ponds in the development of conspicuous phytoplankton blooms often dominated by bloom-forming cyanobacteria. The list of the main cyanobacterial genera and the ponds where they occurred during the study period is given in Table 1 .

An RDA (Fig. 1) allowed the variables having the strongest relationship with the phytoplankton in general and cyanobacteria in particular to be identified. The first two RDA axes explained $40 \%$ and $4 \%$ of the variation in the phytoplankton data respectively. As indicated by the Secchi depth arrow, the first axis corresponds to a phytoplankton biomass gradient ( $r=-0.87$; Fig. 1). Chl $a$ and Secchi depth showed highly significant relationships with phytoplankton biovolumes $(P<0.01)$, suggesting that the latter give a reasonable estimation of phytoplankton biomass and that the turbidity in the ponds studied is mostly phytoplankton induced. To avoid the blurring effect of Chl $a$, Secchi depth and TP (the proxies of phytoplankton biomass) on other environmental variables, they were excluded from the model in forward selection analysis. After their exclusion, five variables showed significant relationships with the phytoplankton data (Table 2). These are large Cladocera length, $\mathrm{pH}$, submerged vegetation cover, temperature and SRP. They explained $26 \%, 6 \%, 6 \%, 3 \%$ and $3 \%$ variation in the phytoplankton data respectively (LambdaA, Table 2). Contrary to large Cladocera length, large Cladocera density showed poor relationship with the phytoplankton data.

Cyanobacteria are clearly separated by the RDA from other phytoplankton groups that, with the exception of chrysophytes, form a tight cluster around the temperature arrow (Fig. 1). Phytoplankters from these groups could be found in most of the ponds studied. Cyanobacteria show 

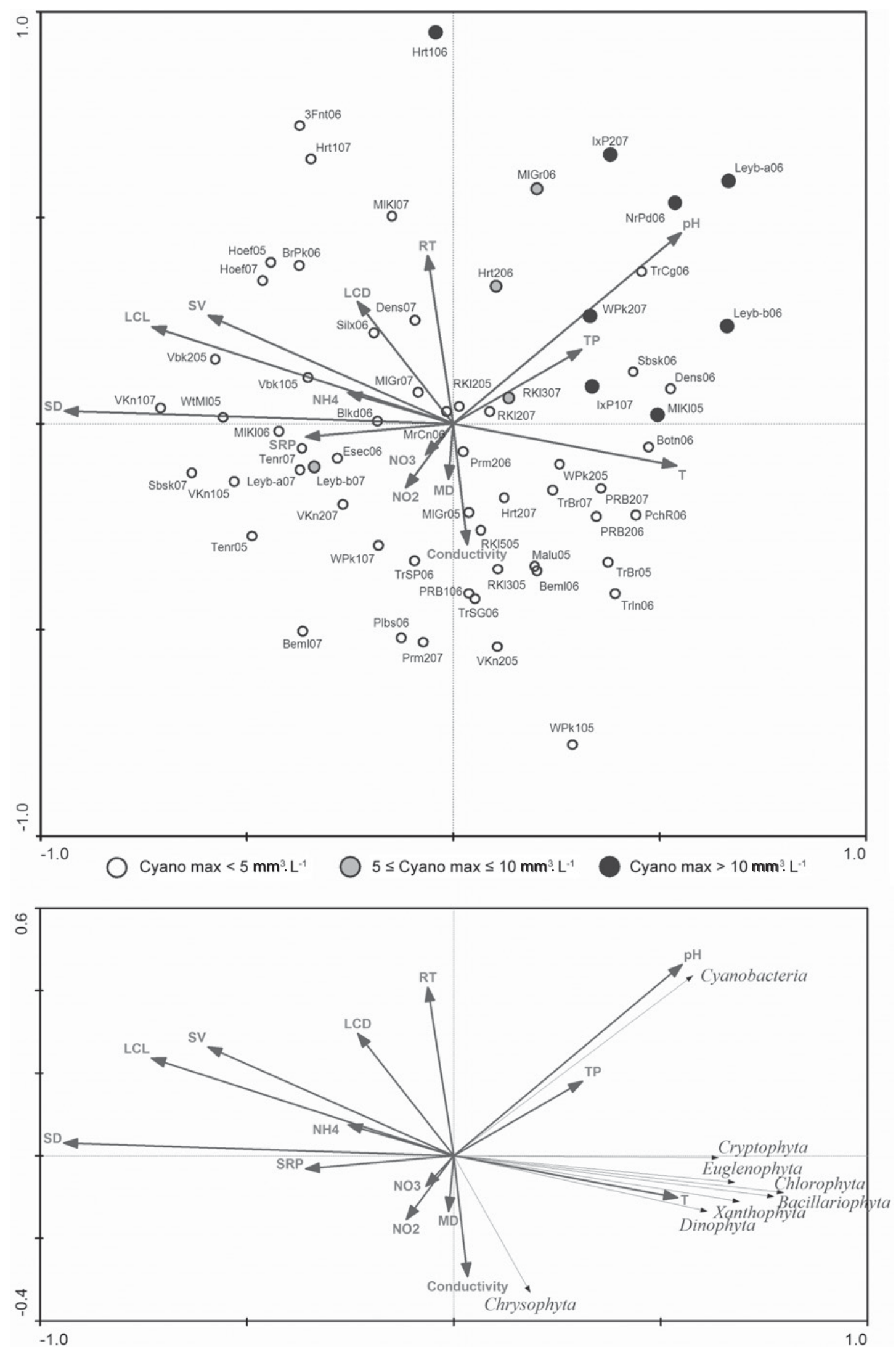

Fig. 1. RDA biplots based on averaged per year phytoplankton and environmental data. Phytoplankton biovolumes are aggregated to division level; top - sites and environmental variables biplot, site symbols show maximum cyanobacterial biovolume split into three levels: $<5 \mathrm{~mm}^{3} . \mathrm{L}^{-1}, 5-10 \mathrm{~mm}^{3} . \mathrm{L}^{-1}$ and $>10 \mathrm{~mm}^{3} . \mathrm{L}^{-1}$; bottom - phytoplankton divisions and environmental variables biplot. The last two digits in the pond names indicate the sampling year. For the abbreviations of environmental variables see Table 2. 
Table 2. RDA forward selection results. Marginal effects show the variance explained by each environmental variable alone (Lambda1); conditional effects show the significance of the addition of a given variable $(P)$ and the additional variance explained at a time the variable was included into the model (LambdaA). LCL - large Cladocera length, SV - \% submerged vegetation cover, $\mathrm{T}$-temperature, $\mathrm{SRP}$-soluble reactive phosphorus, LCD-large Cladocera density, Condconductivity, MD - maximum depth, RT-hydraulic retention time.

\begin{tabular}{|c|c|c|c|c|}
\hline \multicolumn{2}{|c|}{ Marginal effects } & \multicolumn{2}{|c|}{ Conditional effects } & \multirow[b]{2}{*}{$P$} \\
\hline$\overline{\text { Variable }}$ & $\overline{\text { Lambda } 1}$ & $\overline{\text { Variable }}$ & $\overline{\text { LambdaA }}$ & \\
\hline$\overline{\mathrm{LCL}}$ & 0.26 & $\overline{\mathrm{LCL}}$ & 0.26 & 0.002 \\
\hline SV & 0.17 & $\mathrm{pH}$ & 0.06 & 0.002 \\
\hline $\mathrm{pH}$ & 0.16 & SV & 0.06 & 0.004 \\
\hline $\mathrm{T}$ & 0.14 & $\mathrm{~T}$ & 0.03 & 0.014 \\
\hline SRP & 0.07 & SRP & 0.03 & 0.016 \\
\hline LCD & 0.04 & $\mathrm{NH}_{4}$ & 0.01 & 0.310 \\
\hline $\mathrm{NH}_{4}$ & 0.04 & Cond & 0.01 & 0.302 \\
\hline $\mathrm{NO}_{2}$ & 0.02 & $\mathrm{LCD}$ & 0.02 & 0.154 \\
\hline Cond & 0.01 & MD & 0.01 & 0.424 \\
\hline MD & 0.01 & RT & 0.00 & 0.572 \\
\hline RT & 0.01 & $\mathrm{NO}_{3}$ & 0.01 & 0.532 \\
\hline $\mathrm{NO}_{3}$ & 0.01 & $\mathrm{NO}_{2}$ & 0.01 & 0.710 \\
\hline
\end{tabular}

positive correlation with $\mathrm{pH}(r=0.54)$. The ponds with maximum annual biovolumes of cyanobacteria exceeding $5 \mathrm{~mm}^{3} \cdot \mathrm{L}^{-1}$ are mostly confined to the second quadrant of the biplot (Fig. 1) corresponding to conditions of high $\mathrm{pH}$, but also elevated temperature and retention time, as indicated by the respective arrows. These ponds were also lacking submerged vegetation and were dominated by small zooplankters.

Multiple regression analysis showed that only phytoplankton biomass (biovolume, Chl $a$ or Secchi depth) and $\mathrm{pH}$ have significant relationship with cyanobacterial biovolumes $(P<0.001)$. The other variables showed poor relationship with cyanobacteria (Fig. 2). Despite significant relationship, phytoplankton biovolumes and $\mathrm{pH}$ explained only $30 \%$ of the variation in cyanobacteria data.

The scatter plots revealed, however, that some environmental variables $(\mathrm{pH}$, large Cladocera length, retention time, maximum depth and temperature) have threshold rather than linear relationships with cyanobacteria. The majority of cyanobacterial blooms observed during the five year study occurred at $\mathrm{pH}$ above 8 (Fig. 2a). The few that occurred at $\mathrm{pH}$ below 8 were of markedly lower magnitude than the former. No cyanobacterial blooms were observed in ponds where mean large Cladocera length exceeded $1 \mathrm{~mm}$ (Fig. 2b). The same is true for hydraulic retention time below 10 days and temperature below $14{ }^{\circ} \mathrm{C}$ (Figs. 2c and 2e). Elevated concentrations of cyanobacteria were observed only on two occasions in ponds deeper than $2 \mathrm{~m}$ (Fig. 2d). The last two thresholds could be due to the lack of data on ponds with colder water temperature and greater depth. In our dataset, the warm season water temperature is mostly above $14{ }^{\circ} \mathrm{C}$, and there are only two ponds deeper than $2 \mathrm{~m}$.
Cyanobacterial biomass was generally very low in ponds harbouring submerged vegetation (Fig. 2f). No blooms were observed in ponds with submerged vegetation cover exceeding 20\%. Conversely, severe cyanobacterial blooms were generally associated with low DIN concentrations (Fig. 2g) and were often dominated by the heterocystous cyanobacteria (Anabaena spp., Aphanizomenon spp., Anabaenopsis spp.) capable of fixing nitrogen (Graham and Wilcox, 2000). It should be noted, however, that high levels of phytoplankton biomass dominated by other phytoplankton groups were also associated with low DIN concentrations, whereas cyanobacterial blooms could be associated with both low and high DIN concentrations. Besides, cyanobacterial blooms that occurred at low DIN levels were often dominated by non-heterocystous cyanobacteria (Planktothrix spp., Microcystis spp., Limnothrix spp.), while cyanobacterial blooms that occurred at elevated DIN levels could be dominated by the heterocystous cyanobacteria (Fig. $2 \mathrm{~g}$; the two highest points of cyanobacterial biomass correspond to a bloom of Anabaenopsis sp. that occurred at elevated DIN concentrations). This suggests that nitrogen has poor predictive capacity for cyanobacterial blooms in the ponds studied.

Cyanobacterial blooms were invariably associated with high phytoplankton biomass $\left(>13 \mathrm{~mm}^{3} \cdot \mathrm{L}^{-1}\right)$. However, not all ponds with high phytoplankton biomass developed cyanobacterial blooms. In some ponds, high phytoplankton biomass was dominated by other algae with cyanobacteria playing a minor role or absent (Fig. 2h). High phytoplankton biomass dominated by cyanobacteria was associated with high $\mathrm{pH}$ (mostly $>8$ ), whereas in case of dominance by other phytoplankters $\mathrm{pH}$ was relatively low $($ mostly $<8)$.

Dominant phytoplankton groups could change seasonally and from year to year. Because of non-linear relationships between cyanobacteria and environmental factors and high stochasticity in the compositional dynamics of phytoplankton, a probabilistic approach was used to estimate the risk of occurrence of cyanobacterial blooms in the ponds studied. As high concentrations of cyanobacteria were more likely to occur above or below the thresholds identified through the scatter plot analysis (Fig. 2), these thresholds were used for the calculation of conditional probabilities of cyanobacterial bloom occurrence. The results of the probability calculation are summarised in Table 3 and Figure 3. The probability of cyanobacterial bloom occurrence during the summer months in Brussels ponds is relatively low -27 bloom cases out of 381 sampling occasions $(27 / 381=0.07$; no condition). This probability showed a considerable seasonal $(0.02-0.15)$ and interannual $(0.01-0.10)$ variation. It should be noted that the number of ponds sampled and sampling frequency varied from year to year and from month to month. This implies that some years are more representative of the whole population of the Brussels ponds than the others. This effect is minimised by the relatively large number of ponds sampled each year $(>15)$ as well as the large number of sampling occasions (mostly $>60$ ) used in each calculation. 

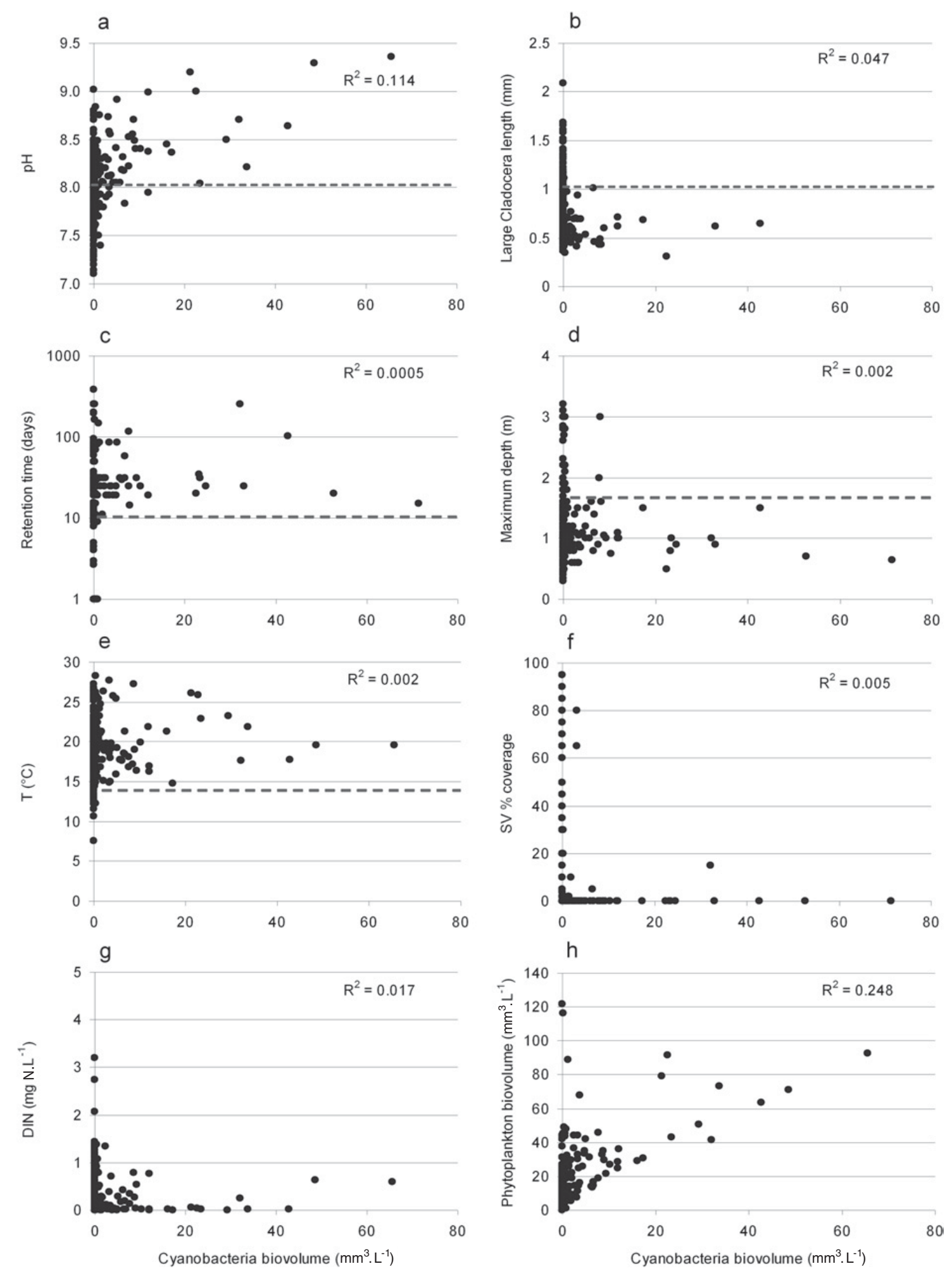

Fig. 2. Scatter plots showing relationships between cyanobacteria and environmental variables in the ponds studied; dashed lines indicate the thresholds in the distribution of cyanobacterial biomass along a given gradient.

Using thresholds for the calculation of conditional probabilities allowed substantial reduction of the sample size with the minimal loss of cyanobacterial blooms, i.e. blooms unaccounted by the model (e.g. 381 cases, 27 blooms - no condition; 172 cases, 26 blooms given that
$\mathrm{pH}>8,1$ unaccounted cyanobacterial bloom). Reduction in the sample size used in conditional probability calculation is reflected in the probability values (Table 3 ) that are considered as a measure of predictive capacity of the model. This allows the comparison of predictive capacities 
Table 3. Calculation of the probability of cyanobacterial bloom (cyanobacterial biovolume $>5 \mathrm{~mm}^{3} . \mathrm{L}^{-1}$ ) occurrence for data subsets corresponding to different time scales (seasonal, interannual and overall the study period) and environmental conditions (conditional probability). Number of bloom cases accounted by the model/total number of cases = probability of bloom; $\times$ - intersection between different conditions; combined conditions use the same thresholds as those indicated for individual conditions; "-" no data; MD - maximum depth; T - temperature; RT - hydraulic retention time; LCL - large Cladocera length; SV - submerged vegetation cover; Biovol - total phytoplankton biovolume; SD - Secchi depth; CyanoHistory - history of cyanobacterial blooms.

\begin{tabular}{|c|c|c|c|c|c|c|c|c|c|}
\hline & 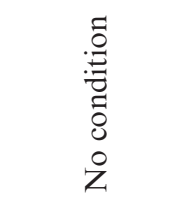 & 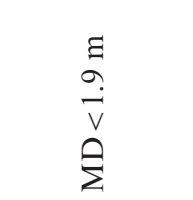 & $\begin{array}{l}U \\
0 \\
\Delta \\
\hat{H}\end{array}$ & 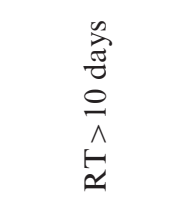 & 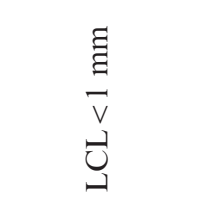 & $\begin{array}{l}\infty \\
\hat{I} \\
\stackrel{I}{2}\end{array}$ & $\begin{array}{l}\dot{0}^{\circ} \\
\stackrel{N}{v} \\
i n\end{array}$ & 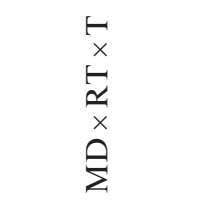 & $\begin{array}{l}\vec{z} \\
\times \\
x \\
\vec{z}\end{array}$ \\
\hline May & $2 / 96=0.02$ & $2 / 90=0.02$ & $2 / 72=0.03$ & $2 / 79=0.03$ & $1 / 43=0.02$ & $2 / 46=0.04$ & $2 / 71=0.03$ & $2 / 61=0.03$ & $2 / 34=0.06$ \\
\hline June & $2 / 70=0.03$ & $2 / 63=0.03$ & $2 / 70=0.03$ & $2 / 51=0.04$ & $1 / 28=0.04$ & $2 / 31=0.06$ & $2 / 43=0.05$ & $2 / 44=0.05$ & $2 / 21=0.10$ \\
\hline July & $8 / 78=0.10$ & $6 / 70=0.09$ & $8 / 78=0.10$ & $8 / 65=0.12$ & $6 / 47=0.13$ & $8 / 37=0.22$ & $8 / 58=0.14$ & $6 / 59=0.10$ & $8 / 29=0.28$ \\
\hline August & $9 / 62=0.15$ & $9 / 59=0.15$ & $9 / 60=0.15$ & $9 / 56=0.16$ & $7 / 49=0.14$ & $9 / 29=0.31$ & $9 / 48=0.19$ & $9 / 53=0.17$ & $9 / 25=0.36$ \\
\hline September & $6 / 75=0.08$ & $6 / 64=0.09$ & $6 / 55=0.11$ & $6 / 59=0.10$ & $2 / 29=0.07$ & $5 / 29=0.17$ & $6 / 57=0.11$ & $6 / 39=0.15$ & $5 / 24=0.21$ \\
\hline 2003 & $2 / 48=0.04$ & $2 / 42=0.05$ & $2 / 40=0.05$ & $2 / 33=0.06$ & - & $2 / 24=0.08$ & $2 / 31=0.06$ & $2 / 26=0.08$ & $2 / 17=0.12$ \\
\hline 2004 & $6 / 64=0.09$ & $6 / 56=0.11$ & $6 / 62=0.10$ & $6 / 44=0.14$ & - & $5 / 36=0.14$ & $6 / 45=0.13$ & $6 / 37=0.16$ & $5 / 26=0.19$ \\
\hline 2005 & $1 / 80=0.01$ & $1 / 69=0.01$ & $1 / 56=0.02$ & $1 / 55=0.02$ & $1 / 53=0.02$ & $1 / 6=0.17$ & $1 / 57=0.02$ & $1 / 35=0.03$ & $1 / 5=0.20$ \\
\hline 2006 & $8 / 81=0.10$ & $8 / 81=0.10$ & $8 / 79=0.10$ & $8 / 81=0.10$ & $7 / 69=0.10$ & $8 / 46=0.17$ & $8 / 70=0.11$ & $8 / 79=0.10$ & $8 / 39=0.21$ \\
\hline 2007 & $10 / 108=0.09$ & $8 / 98=0.08$ & $10 / 98=0.10$ & $10 / 97=0.10$ & $9 / 74=0.12$ & $10 / 60=0.17$ & $10 / 74=0.14$ & $8 / 79=0.10$ & $10 / 46=0.22$ \\
\hline Overall & $27 / 381=0.07$ & $25 / 346=0.07$ & $27 / 335=0.08$ & $27 / 310=0.09$ & $17 / 196=0.09$ & $26 / 172=0.15$ & $27 / 277=0.10$ & $25 / 256=0.10$ & $26 / 133=0.20$ \\
\hline
\end{tabular}

\begin{tabular}{|c|c|c|c|c|c|c|c|c|c|}
\hline & 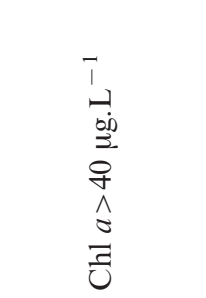 & 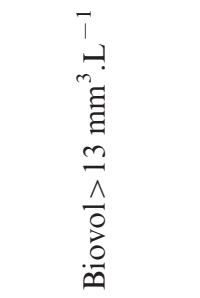 & 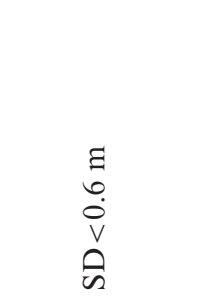 & $\begin{array}{l}\overrightarrow{0} \\
0 \\
0 \\
0 \\
x \\
x \\
2 \\
x \\
x \\
\overrightarrow{1} \\
2\end{array}$ & 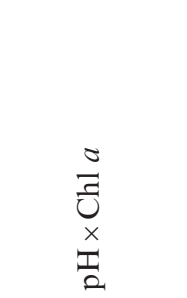 & $\begin{array}{l}\overline{0} \\
\stackrel{0}{0} \\
.0 \\
x \\
x \\
a \\
a\end{array}$ & $\begin{array}{l}\stackrel{0}{2} \\
\times \\
\stackrel{x}{2}\end{array}$ & 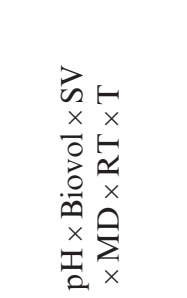 & 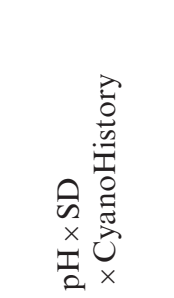 \\
\hline May & $2 / 14=0.14$ & $2 / 24=0.08$ & $2 / 22=0.09$ & $2 / 15=0.13$ & $2 / 9=0.22$ & $2 / 15=0.13$ & $2 / 14=0.14$ & $2 / 15=0.13$ & $2 / 9=0.22$ \\
\hline June & $2 / 16=0.13$ & $2 / 17=0.12$ & $2 / 16=0.13$ & $2 / 10=0.20$ & $2 / 11=0.18$ & $2 / 10=0.20$ & $2 / 11=0.18$ & $2 / 7=0.29$ & $2 / 9=0.22$ \\
\hline July & $8 / 34=0.24$ & $8 / 30=0.27$ & $8 / 24=0.33$ & $8 / 20=0.40$ & $8 / 24=0.33$ & $8 / 20=0.40$ & $8 / 19=0.42$ & $6 / 17=0.35$ & $8 / 11=0.73$ \\
\hline August & $8 / 30=0.27$ & $9 / 25=0.36$ & $8 / 22=0.36$ & $9 / 19=0.47$ & $8 / 22=0.36$ & $9 / 19=0.47$ & $8 / 18=0.44$ & $9 / 19=0.47$ & $8 / 10=0.80$ \\
\hline September & $4 / 25=0.16$ & $6 / 25=0.24$ & $6 / 20=0.30$ & $5 / 14=0.36$ & $3 / 13=0.23$ & $5 / 15=0.33$ & $5 / 11=0.45$ & $5 / 10=0.50$ & $5 / 10=0.50$ \\
\hline 2003 & - & $2 / 10=0.20$ & $2 / 15=0.13$ & $2 / 7=0.29$ & - & $2 / 8=0.25$ & $2 / 10=0.20$ & $2 / 5=0.40$ & $2 / 8=0.25$ \\
\hline 2004 & $6 / 19=0.32$ & $6 / 16=0.38$ & $6 / 20=0.30$ & $5 / 11=0.45$ & $5 / 14=0.36$ & $5 / 11=0.45$ & $5 / 14=0.36$ & $5 / 10=0.50$ & $5 / 12=0.42$ \\
\hline 2005 & $1 / 25=0.04$ & $1 / 27=0.04$ & $1 / 15=0.07$ & $1 / 5=0.20$ & $1 / 5=0.20$ & $1 / 5=0.20$ & $1 / 3=0.33$ & $1 / 3=0.33$ & $1 / 3=0.33$ \\
\hline 2006 & $7 / 32=0.22$ & $8 / 34=0.24$ & $8 / 31=0.26$ & $8 / 28=0.29$ & $7 / 25=0.28$ & $8 / 28=0.29$ & $8 / 26=0.31$ & $8 / 28=0.29$ & $8 / 11=0.73$ \\
\hline 2007 & $10 / 43=0.23$ & $10 / 34=0.29$ & $9 / 23=0.39$ & $10 / 27=0.37$ & $10 / 35=0.29$ & $10 / 27=0.37$ & $9 / 20=0.45$ & $8 / 22=0.36$ & $9 / 15=0.60$ \\
\hline Overall & $24 / 119=0.20$ & $27 / 121=0.22$ & $26 / 104=0.25$ & $26 / 78=0.33$ & $23 / 79=0.29$ & $26 / 79=0.33$ & $25 / 73=0.34$ & $24 / 68=0.35$ & $25 / 49=0.51$ \\
\hline
\end{tabular}



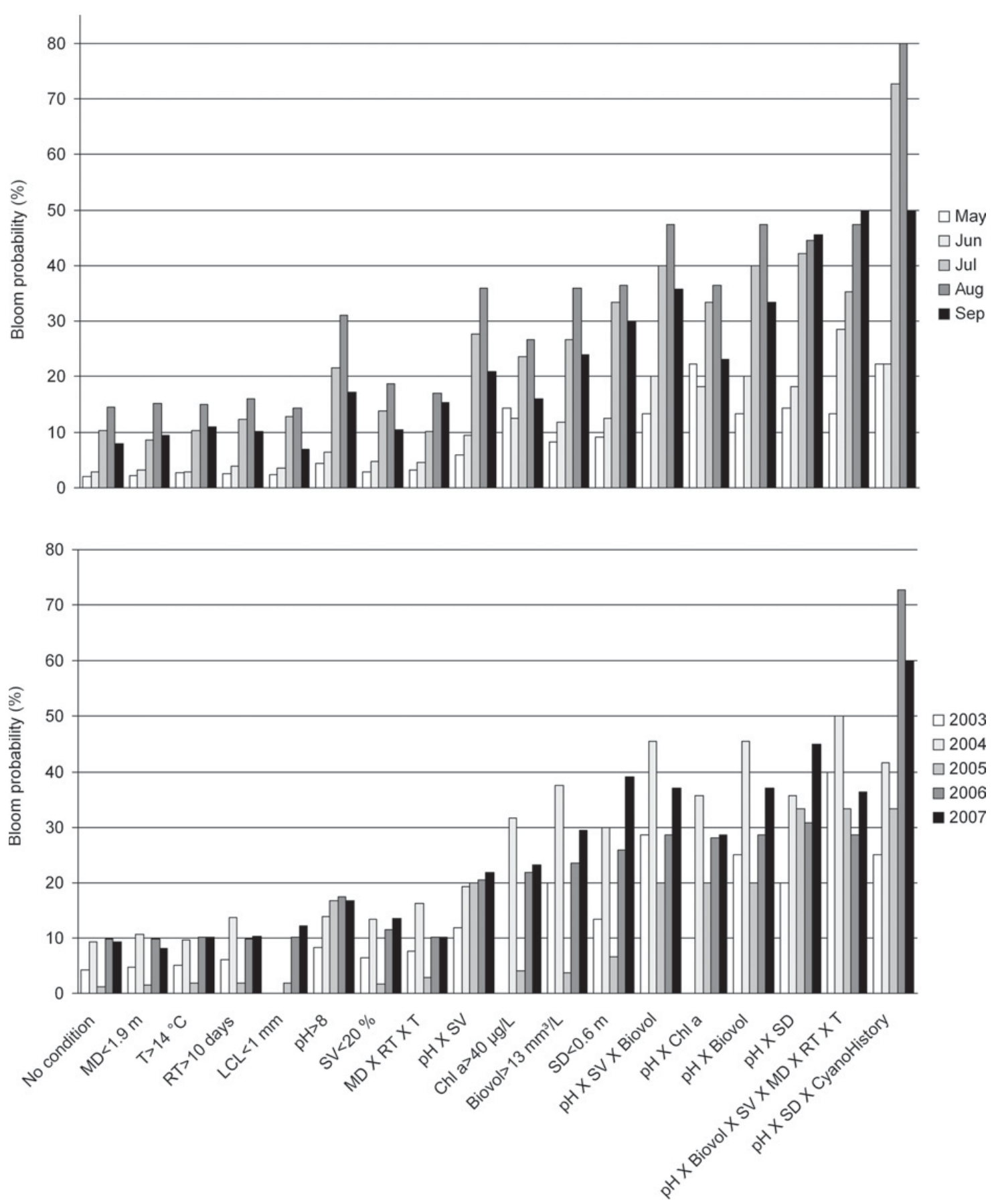

Fig. 3. Seasonal and inter-annual variations in the unconditional and conditional probabilities of cyanobacterial bloom occurrence in the ponds studied. The higher probability values indicate higher predictive capacity. For abbreviations see Table 3.

of different environmental factors or their combinations (e.g. in 2007, 10 blooms are present in the sample of 60 cases with $\mathrm{pH}>8$, probability: $10 / 60=0.17$ and 10 blooms are present in the sample of 98 cases with temperature $>14{ }^{\circ} \mathrm{C}$ : probability $10 / 98=0.10$; thus $\mathrm{pH}$ has greater predictive capacity for cyanobacterial blooms than temperature).

Phytoplankton biomass (Secchi depth, biovolume, $\mathrm{Chl} a$ ) and $\mathrm{pH}$ rendered the highest probability values among the individual environmental factors used in probability calculation (Table 3; Fig. 3).
The intersection between the effects of different factors (individual conditions) allows further reduction of the sample size to cases with the higher likelihood of cyanobacterial bloom occurrence. Thus, using a combination of factors as conditions allows the calculation of respective probabilities. The higher probability values correspond to the higher predictive capacity for cyanobacterial blooms (Fig. 3). The combination of $\mathrm{pH}$, phytoplankton biovolume, submerged vegetation cover, maximum depth, retention time and temperature used as condition for the bloom probability calculation gave 


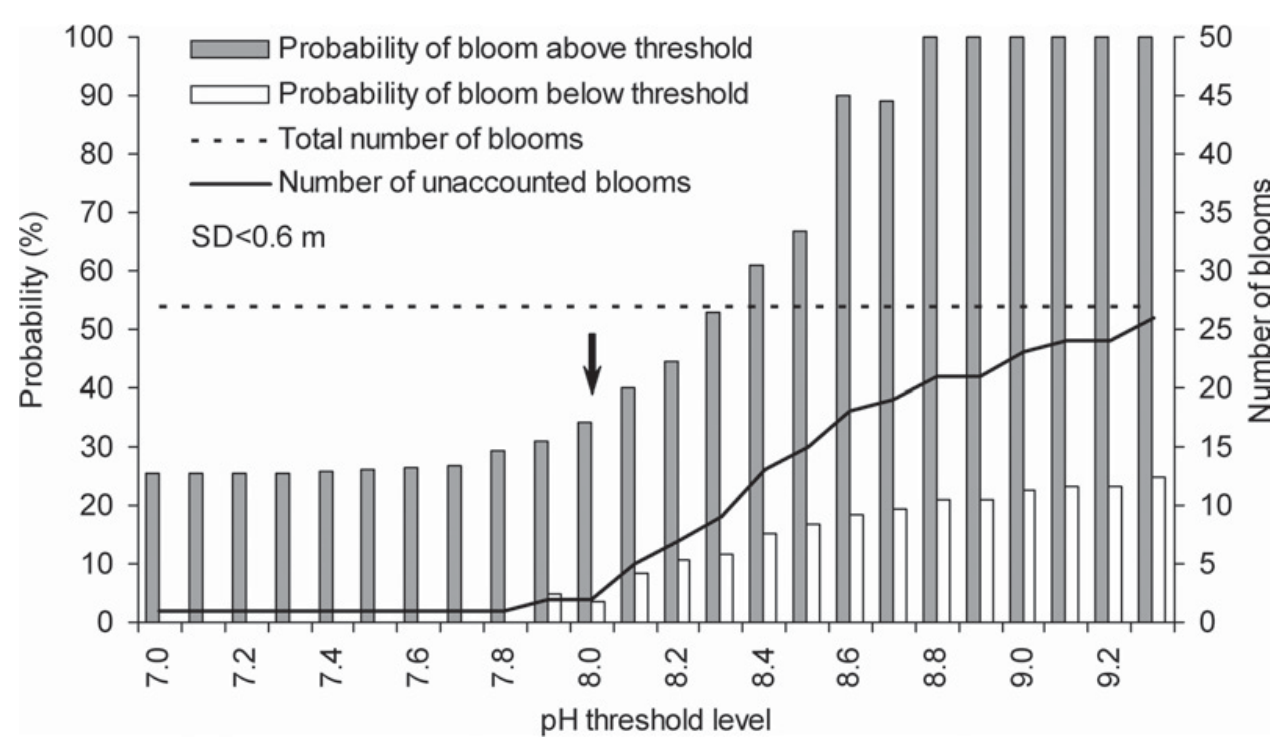

Fig. 4. Cyanobacterial bloom probabilities with Secchi depth and $\mathrm{pH}$ used as conditions; Secchi depth threshold fixed at $0.6 \mathrm{~m}$, $\mathrm{pH}$ threshold variable. Calculation is done for probabilities above and below the $\mathrm{pH}$ threshold. The threshold level allowing maximum probability value with minimal number of cyanobacterial blooms unaccounted by the model is indicated by an arrow.

the highest probability values based on environmental factors (Table 3; Fig. 3). The probability values (overall, per month and per year) corresponding to different environmental factors or their combinations were compared using the Wilcoxon matched pairs test. The results of the test showed that two combinations, $\mathrm{pH}$ and phytoplankton biovolume and $\mathrm{pH}$ and Secchi depth, gave the probabilities that are not significantly different from those given by the combination of all the factors together (Wilcoxon matched pairs test; $P=0.07$ and 0.28 respectively).

Adding the history of cyanobacterial blooms as a condition in probability calculation (restricting the sample size to ponds that had cyanobacterial blooms during the study period) further increased probability values and thus predictive capacity of the model (Table 3; Fig. 3).

The model run for Secchi depth threshold fixed at $0.6 \mathrm{~m}$ and $\mathrm{pH}$ threshold variable (Fig. 4) shows that $\mathrm{pH} 8$ is the breakpoint beyond which the probability of bloom occurrence starts to increase rapidly, reaching $100 \%$ at $\mathrm{pH}>8.8$. This implies that at such conditions cyanobacterial blooms become virtually inevitable in the ponds studied. On the other hand, the probability of bloom occurrence below the breakpoint is mostly 0 or close to it.

The rapid increase in bloom probability after the breakpoint is accompanied with the increase in the number of blooms unaccounted by the model (i.e. blooms that occurred below the $\mathrm{pH}$ thresholds; Fig. 4). Therefore moving threshold beyond the breakpoint diminishes the capacity of the model to predict cyanobacterial blooms in general. It allows, however, the conditions at which the risk of bloom occurrence is the highest to be identified. Above pH 8.8 every sampling corresponds to a cyanobacterial bloom, while almost all blooms are confined to the area of $\mathrm{pH}>8$ and Secchi depth $<0.6 \mathrm{~m}$ (Fig. 5; top).

The model also allows the stepwise calculation of bloom probability for different ranges of factors or their combinations. The result of the model run for the relatively narrow ranges of $\mathrm{pH}(\mathrm{step}=0.5)$ and Secchi depth $($ step $=0.25)$ is shown on Figure 5 (bottom). This permits to assess the risk of bloom occurrence for particular environmental conditions, which further improves the predictive capacity of the model.

The probabilistic model developed can be run for different ranges or levels of environmental thresholds or their combinations as well as for different magnitudes of cyanobacterial blooms. This results in an automatic update of the calculation output (Table 3, Figs. 3 and 5). Beside the quantification of the risk of cyanobacterial bloom occurrence corresponding to different conditions in the ponds studied, the model permits to visualise the distribution of cyanobacterial blooms of a given magnitude as well as conditions propitious for bloom development (shown as coloured cells on the data matrix) in space (pond) and time (sampling campaign).

\section{Discussion}

While phytoplankton biomass levels in ponds and lakes can be predicted fairly accurately, predicting compositional changes is much more difficult because phytoplankton composition depends on a large number of interrelated environmental factors subject to stochastic changes (Reynolds, 1998, 2000). The outcomes of stochastic interaction between different factors can not be predicted with certainty. Under certain conditions some phytoplankters, however, tend to increase in biomass more strongly than others suggesting that their recruitment and dominance are not completely stochastic and that some factors favour them more than other species. Hence they become at least temporarily more represented. The patterns in the relationships between environmental 

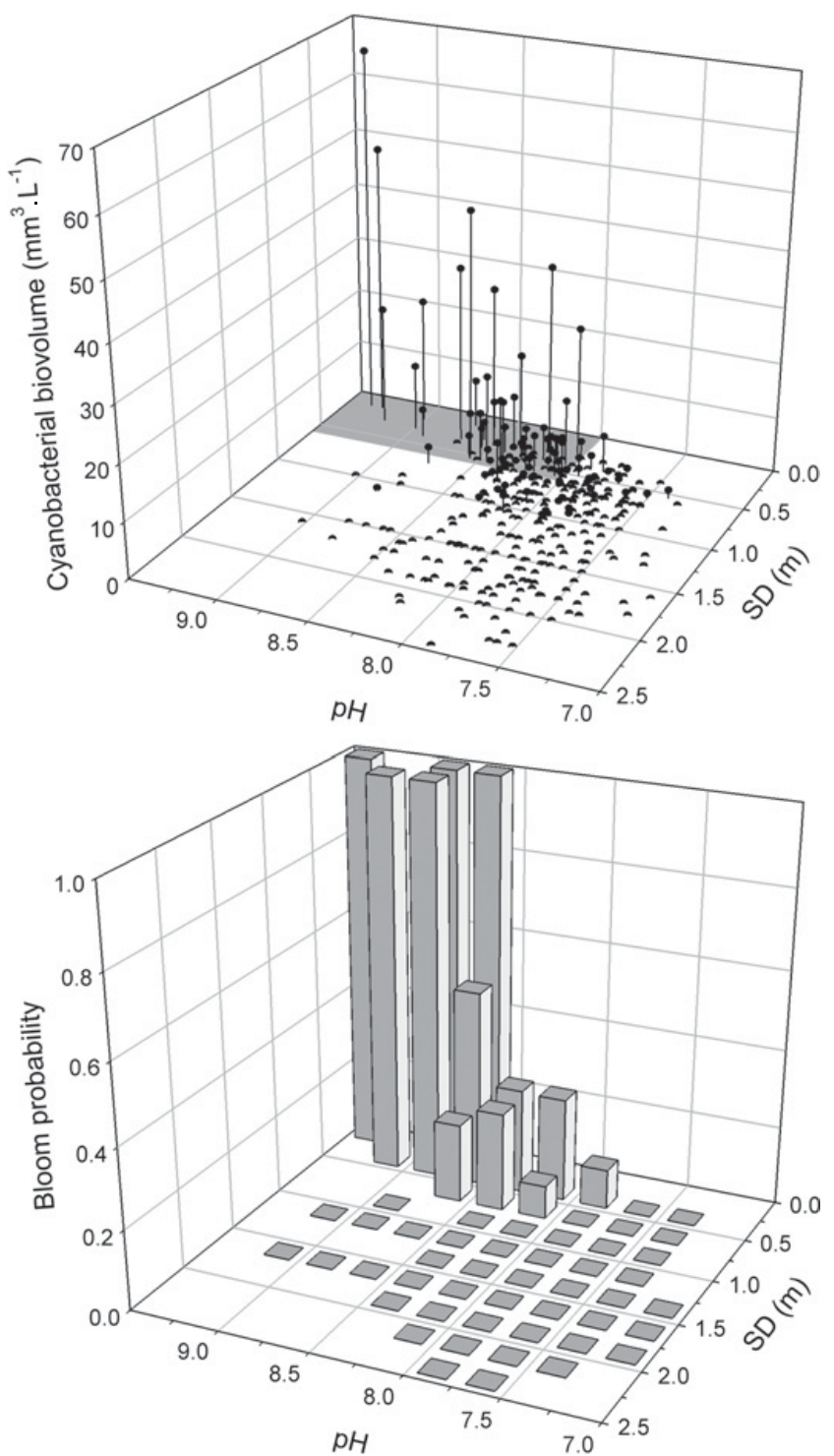

Fig. 5. Top: relationship of cyanobacterial biovolume to Secchi depth and $\mathrm{pH}$ based on all samples used in the model. Grey area corresponds to the conditions with high risk of cyanobacterial bloom occurrence: $\mathrm{pH}>8$, Secchi depth $<0.6 \mathrm{~m}$. Bottom: model output showing cyanobacterial bloom probability corresponding to different ranges of $\mathrm{pH}$ and Secchi depth calculated stepwise (step length: $\mathrm{pH}=0.5$, Secchi depth $=0.25 \mathrm{~m}$ ).

conditions and phytoplankton responses to them allow predicting changes in phytoplankton assemblages. Phytoplankters with a broad adaptive overlap are able to constitute phytoplankton assemblages characteristic of a range of conditions. More specialized phytoplankters are preferentially selected by conditions they developed adaptations for and, when these conditions persist, can become dominant (Reynolds, 1998, 2006).

The ponds studied showed high temporal and interpond variability in environmental conditions. Phytoplankton assemblages reflected this variability to a considerable degree. Many phytoplankters, however, were present in most of the ponds. This suggests high dispersive mobility of phytoplankton and broad overlap in adaptive attributes. The latter is supported by the RDA results: most of the phytoplankton groups are clustered together along the temperature arrow. Cyanobacteria stand apart as a group and show an affinity to elevated $\mathrm{pH}$ conditions. Indeed, the great majority of cyanobacterial blooms occurred at $\mathrm{pH}$ above 8 (Fig. 2a). This is consistent with the idea that cyanobacteria are better adapted than other phytoplankton groups to low $\mathrm{CO}_{2}$ concentrations characteristic of high pH conditions (Shapiro, 1973, 1997). Being favoured by increased temperature similar to other phytoplankton groups, cyanobacteria are much more sensitive to flushing due to relatively low growth rates (Scheffer, 1998; Reynolds, 2006). This is reflected in the RDA results: the ponds with cyanobacterial blooms are mostly confined to the biplot area that beside high $\mathrm{pH}$ is characterised by high temperature and hydraulic retention time.

It seems certain that the likelihood of cyanobacterial bloom development depends to a considerable degree on environmental conditions. This is consistent with other reports (Dokulil and Teubner, 2000; Downing et al., 2001; Rinta-Kanto et al., 2009) and the results of biomanipulation of some of the Brussels ponds with long history of persistent cyanobacterial blooms, where change in environmental conditions caused by biomanipulation (mainly increase in large zooplankton grazing and restoration of submerged vegetation) was sufficient to prevent bloom formation (Peretyatko et al., 2009). The ponds where conditions favouring cyanobacteria persist are more likely to develop blooms. This is supported by the results of the RDA that clearly separate cyanobacteria from other phytoplankton groups and indicate the conditions that favour them as well as ponds prone to such conditions. Although informative, the RDA has limited predictive capacity. The same is true for the regression analysis of the data acquired due to threshold rather than linear relationships between cyanobacteria and environmental factors. Threshold relationships allow, however, the likelihood of cyanobacterial bloom occurrence to be quantified in terms of conditional probabilities. The intersections between different environmental conditions favouring cyanobacterial blooms permit to identify the conditions that are the most propitious to bloom development as well as the ponds that are prone to such conditions.

There is a substantial overlap in factors that favour cyanobacteria. The shallower ponds, for example, are mostly warmer and, given high nutrient availability, develop higher phytoplankton biomass. This generally leads to an increase in $\mathrm{pH}$ that integrates to a considerable degree the effects of depth and temperature. It should be noted that we observed high phytoplankton biomass associated with relatively low $\mathrm{pH}$ (Fig. 5; $\mathrm{pH}<8$; SD $<0.6$ ). In most of such cases phytoplankton assemblages were dominated by phytoplankters other than cyanobacteria. This suggests that at lower $\mathrm{pH}$ levels other phytoplankters are more competitive, which can probably be attributed to the slower rates of growth of bloomforming cyanobacteria (Reynolds, 2006). 
Large Cladocera size seems to be an important factor in cyanobacterial bloom control. No cyanobacterial blooms were observed in the ponds where mean cladoceran length exceeded $1 \mathrm{~mm}$. These ponds either harboured extensive submerged vegetation or had no or very low densities of fish. In the first case the lack of cyanobacteria could be attributed, at least in part, to submerged vegetation presence (Søndergaard and Moss, 1998; Van Donk and Van De Bund, 2002; Peretyatko, 2007). The second case suggests, however, that when the predation pressure is low, large cladocerans can grow big enough to be able to control even grazing resistant cyanobacteria. Intense zooplankton grazing results in low phytoplankton biomass, which is subsequently reflected on the pond $\mathrm{pH}$. The same is true for hydraulic retention time that plays an important role in phytoplankton biomass control in small waterbodies (Reynolds, 2006; Peretyatko et al., 2007b).

Intensive growth of submerged vegetation (submerged macrophytes and/or green filamentous algae) is also known to inhibit phytoplankton growth through a number of associated mechanisms (Søndergaard and Moss, 1998; Van Donk and Van De Bund, 2002; Peretyatko, 2007). In contrast to the factors described above, phytoplankton biomass decrease due to the competition with submerged vegetation is generally associated with high $\mathrm{pH}$ owing to the photosynthetic activity of the macrophytes. Therefore, excluding the ponds with submerged vegetation will further reduce the sample size without losing cases of cyanobacterial blooms, thus increasing the predictive capacity of the model (see $\mathrm{pH}>8$ and $\mathrm{pH} \times \mathrm{SV}$; Table 3 , Fig. 3 )

Cyanobacterial blooms, however, are invariably associated with high phytoplankton biomass. The ponds with high phytoplankton biomass mostly lack submerged vegetation. This implies that the use of phytoplankton biomass (Secchi depth, biovolume or Chl a) as the condition for the probability calculation makes submerged vegetation cover largely redundant (see $\mathrm{pH} \times \mathrm{SV} \times$ Biovol and $\mathrm{pH} \times$ Biovol; Table 3, Fig. 3).

Beside submerged vegetation, phytoplankton biomass integrates to a considerable degree the effects of temperature, depth, zooplankton grazing and retention time. This is reflected on the probabilities given by these factors and their combinations (Table 3, Fig. 3). Because of richness in phosphorus and nitrogen, intense phytoplankton growth generally leads to eventual depletion of free $\mathrm{CO}_{2}$ and $\mathrm{pH}$ increase. This gives a competitive advantage to bloomforming cyanobacteria that are well adapted to such conditions (Shapiro, 1973, 1997). When high pH condition persists, cyanobacteria may become dominant. When $\mathrm{pH}$ remains relatively low $(<8)$ despite phytoplankton biomass increase, probably owing to $\mathrm{CO}_{2}$ supply by respiration activity that offset the effect of $\mathrm{CO}_{2}$ consumption by phytoplankton (Brönmark and Hansson, 2005), phytoplankton assemblage is generally dominated by other phytoplankters (Fig. 5, top). Hence, phytoplankton biomass alone is a relatively poor predictor of cyanobacterial blooms, whereas the combination of phytoplankton biomass with $\mathrm{pH}$ considerably increases predictive capacity of the model (Table 3, Fig. 3). This is consistent with the comparative analysis of the predictive capacities of different environmental factors and their combinations rendered by the model. The combination of phytoplankton biomass (Secchi depth or total phytoplankton biovolume) and $\mathrm{pH}$ is the best predictor for cyanobacterial blooms as indicated by Figure 5 (top) showing that the great majority of cyanobacterial blooms are confined to the area corresponding to Secchi depth below $0.6 \mathrm{~m}$ and $\mathrm{pH}$ above 8. Stepwise calculation of bloom probabilities for the consecutive ranges of $\mathrm{pH}$ and Secchi depth allows the risk of bloom occurrence at given ranges of $\mathrm{pH}$ and Secchi depth to be assessed (Fig. 5, bottom). It should be noted that different ranges of $\mathrm{pH}$ and Secchi depth are not equally well represented in the current dataset. Adding data for high $\mathrm{pH}$ ranges will increase the reliability of the model prediction.

Presence of inocula or resting stages of bloom-forming cyanobacteria in a pond considerably increases their potential to outcompete other phytoplankters under favourable conditions (Reynolds, 2006). Adding history of cyanobacterial blooms as a condition into the model increased the probability of bloom occurrence. This supports the idea that the presence of resting stages increases the risk of bloom occurrence, but can also be attributed to the fact that these ponds are prone to conditions that favour cyanobacteria.

The probabilistic approach presented here can not be used to predict the exact date of a cyanobacterial bloom. It allows, however, the risk of occurrence of a cyanobacterial bloom of a given magnitude corresponding to different environmental conditions to be quantified and thus to rank the conditions favouring bloom development and subsequently the ponds where such conditions persist in order of risk increase. The possibility to assess the risk of bloom occurrence on the basis of easily measured variables (pH and Secchi depth) simplifies the application of the model and has important implications for pond management, as it permits rapid identification of the ponds prone to cyanobacterial bloom development and hence can facilitate monitoring planning, remediation efforts and setting restoration priorities.

\section{Conclusions}

Phytoplankton biomass and composition in nutrient rich ponds is controlled by a large number of interrelated environmental factors subject to stochastic changes. Due to specific adaptations of cyanobacteria, certain environmental conditions favour them more than other phytoplankters. When such conditions persist, cyanobacteria can become dominant. Because cyanobacteria have threshold rather than linear relationships with the environmental factors that control them, linear relationships have limited predictive capacity for cyanobacterial blooms. Probabilistic approach permitted the best predictors of cyanobacterial blooms to be identified and, subsequently, the risk of cyanobacterial bloom occurrence 
corresponding to different environmental conditions to be quantified. This allowed the identification of the ponds posing high risk of cyanobacterial bloom development. As the best predictors of blooms are relatively easy to measure, this approach can be applied for the rapid assessment of cyanobacterial bloom risk in nutrient rich ponds and can facilitate the choice of appropriate management interventions.

Acknowledgements. This work was supported by the Brussels Institute of Environment (BIM/IBGE), the Research in Brussels Action 2003-2006 and the Belgian Science Policy and is part of the project "B-Bloom2": "Cyanobacterial blooms: toxicity, diversity, modelling and management"; contract SD/TE/01A.

\section{References}

Agrawal A.A., 1998. Algal defense, grazers, and their interactions in aquatic trophic cascades. Acta Oecol., 19, 331-337.

Benndorf J., Boing W., Koop J. and Neubauer I., 2002. Topdown control of phytoplankton: the role of time scale, lake depth and trophic state. Freshw. Biol., 47, 2282-2295.

Briand J.F., Jacquet S., Bernard C. and Humbert J.F., 2003. Health hazards for terrestrial vertebrates from toxic cyanobacteria in surface water ecosystems. Vet. Res., 34, 1-17.

Brönmark C. and Hansson L.A., 2005. The biology of lakes and ponds, Oxford University Press, Oxford.

Carmichael W.W., 2001. Human fatalities from cyanobacteria: chemical and bioloigical evidence for cyanotoxins. Environ. Health Perspect., 109, 663-668.

Carmichael W., 2008. A world overview - One hundred twenty seven years of research on toxic cyanobacteria - Where do we go from here? In: Hudnell H.K. (ed.), Cyanobacterial harmful algal blooms - State of the science and research needs, Springer Science, 105-120.

Carpenter S.R., Cole J.J., Hodgson J.R., Kitchell J.F., Pace M.L., Bade D., Cottingham K.L., Essington T.E., Houser J.N. and Schindler D.E., 2001. Trophic cascades, nutrients, and lake productivity: whole-lake experiments. Ecol. Monogr., 71, 163-186.

Christoffersen K., Riemann B., Klysner A. and Sondergaard M., 1993. Potential role of fish predation and natural populations of zooplankton in structuring a plankton community in eutrophic lake water. Limnol. Oceanogr., 38, 561-573.

Cottenie K., Nuytten N., Michels E. and De Meester L., 2001. Zooplankton community structure and environmental conditions in a set of interconnected ponds. Hydrobiologia, 442, 339-350.

DeMott W.R., Gulati R.D. and Van Donk E., 2001. Daphnia food limitation in three hypereutrophic Dutch lakes: Evidence for exclusion of large-bodied species by interfering filaments of cyanobacteria. Limnol. Oceanogr., 46, 20542060.

Dokulil M.T. and Teubner K., 2000. Cyanobacterial dominance in lakes. Hydrobiologia, 438, 1-12.

Downing J.A., Watson S.B. and McCauley E., 2001. Predicting Cyanobacteria dominance in lakes. Can. J. Fish. Aquat. Sci., 58, 1905-1908.

Gliwicz Z.M., 1990. Why do cladocerans fail to control algal blooms? Hydrobiologia, 200, 83-97.
Gliwicz Z.M. and Lampert W., 1990. Food thresholds in Daphnia species in the absence and presence of blue-green filaments. Ecology, 71, 691-702.

Graham L.E. and Wilcox L.W., 2000. Algae, Prentice-Hall, Upper Saddle River.

Hasle G.R., 1978. The inverted-microscope method. In: Sournia A. (ed.), Phytoplankton manual, UNESCO, Paris, 88-96.

Hudnell K.H., 2008. Cyanobacterial Harmful Algal Blooms, Springer, New York.

Huisman J., Van Oostveen P. and Weissing F.J., 1999. Species dynamics in phytoplankton blooms: incomplete mixing and competition for light. Am. Nat., 154, 46-68.

Irfanullah H.M. and Moss B., 2005. A filamentous green algae-dominated temperate shallow lake: Variations on the theme of clearwater stable states? Arch. Hydrobiol., 163, 25-47.

Jacquet S., Briand J.F., Leboulanger C., Avois-Jacquet C., Oberhaus L., Tassin B., Vinçon-Leite B., Paolini G., Druart J.-C., Anneville O. and Humbert J.F., 2005. The proliferation of the toxic cyanobacterium Planktothrix rubescens following restoration of the largest natural French lake (Lac du Bourget). Harmful Algae, 4, 651-672.

Jeppesen E., Jensen J.P., Søndergaard M., Lauridsen T., Pedersen L.J. and Jensen L., 1997. Top-down control in freshwater lakes: The role of nutrient state, submerged macrophytes and water depth. Hydrobiologia, 342, 151-164.

Jones J.I., Young J.O., Eaton J.W. and Moss B., 2002. The influence of nutrient loading, dissolved inorganic carbon and higher trophic levels on the interaction between submerged plants and periphyton. J. Ecol., 90, 12-24.

Kemp P.F., Sherr B.F., Sherr E.B. and Cole J.J., 1993. Handbook of methods in aquatic microbial ecology, Lewis Publishers, Boca Raton.

Matveev V., Matveeva L. and Jones G.J., 1994. Study of the ability of Daphnia carinata King to control phytoplankton and resist cyanobacterial toxicity - implications for biomanipulation in Australia. Aust. J. Mar. Freshw. Res., 45, 889-904.

Moss B., Stephen D., Alvarez C., Becares E., Van De Bund W., Collings S.E., Van Donk E., De Eyto E., Feldmann T., Fernandez-Alaez C., Fernandez-Alaez M., Franken R.J.M., Garcia-Criado F., Gross E.M., Gyllstrom M., Hansson L.A., Irvine K., Jarvalt A., Jensen J.P., Jeppesen E., Kairesalo T., Kornijow R., Krause T., Kunnap H., Laas A., Lille E., Lorens B., Luup H., Miracle M.R., Noges P., Noges T., Nykanen M., Ott I., Peczula W., Peeters E., Phillips G., Romo S., Russell V., Salujoe J., Scheffer M., Siewertsen K., Smal H., Tesch C., Timm H., Tuvikene L., Tonno I., Virro T., Vicente E. and Wilson D., 2003. The determination of ecological status in shallow lakes - a tested system (ECOFRAME) for implementation of the European Water Framework Directive. Aquat. Conserv. Mar. Freshw. Ecosyst., 13, 507-549.

Moss B., Barker T., Stephen D., Williams A.E., Balayla D.J., Beklioglu M. and Carvalho L., 2005. Consequences of reduced nutrient loading on a lake system in a lowland catchment: deviations from the norm? Freshw. Biol., 50, 1687-1705.

Oberhaus L., Gélinas M., Pinel-Alloul B., Ghadouani A. and Humbert J.F., 2007. Grazing of two toxic Planktothrix 
species by Daphnia pulicaria: potential for bloom control and transfer of microcystins. J. Plankton Res., 29, 827-838.

Peretyatko A., 2006. Bepaling van de ecologische status van sommige vijvers beheerd door de A.G.R. van het B.I.M., Vrije Universiteit Brussel, Brussels.

Peretyatko A., 2007. Phytoplankton Dynamics in Eutrophic Peri-urban Ponds in Relation to Biotic and Abiotic Factors; Implications for Management and Restoration. Ph.D. Thesis, Vrije Universiteit Brussel, Brussels.

Peretyatko A., Symoens J.J. and Triest L., 2007a. Impact of macrophytes on phytoplankton in eutrophic peri-urban ponds, implications for pond management and restoration. Belg. Journ. Bot., 140, 83-99.

Peretyatko A., Teissier S., Symoens J.J. and Triest L., $2007 \mathrm{~b}$. Phytoplankton biomass and environmental factors over a gradient of clear to turbid peri-urban ponds. Aquat. Conserv. Mar. Freshw. Ecosyst., 17, 584-601.

Peretyatko A., Teissier S., De Backer S. and Triest L., 2009. Restoration potential of biomanipulation for eutrophic peri-urban ponds: the role of zooplankton size and submerged macrophyte cover. Hydrobiologia, 634, 125135.

Pflugmacher S., 2004. Promotion of oxidative stress in the aquatic macrophyte Ceratophyllum demersum during biotransformation of the cyanobacterial toxin microcystin-LR. Aquat. Tox., 70, 169-178.

Pourriot R., 1995. Réponses adaptatives du zooplancton à la prédation. In: Pourriot R. and Meybeck M. (eds.), Limnologie Générale, Masson, Paris, 610-627.

Reynolds C.S., 1998. What factors influence the species composition of phytoplankton in lakes of different trophic status? Hydrobiologia, 369, 11-26.

Reynolds C.S., 2000. Phytoplankton designer - or how to predict compositional responses to trophic-state change. Hydrobiologia, 424, 123-132.

Reynolds C.S., 2006. Ecology of phytoplankton, Cambridge University Press, Cambridge.

Reynolds C.S., Oliver R.L. and Walsby A.E., 1987. Cyanobacterial dominance: the role of buoyancy regulation in dynamic lake environments. N. Z. J. Mar. Freshw. Res., 21, 379-390.
Rinta-Kanto J.M., Konopko E.A., Debruyn J.M., Bourbonniere R.A., Boyer G.L. and Wilhelm S.W., 2009. Lake Erie Microcystis: Relationship between microcystin production, dynamics of genotypes and environmental parameters in a large lake. Harmful Algae, 8, 665-673.

Sanchis D., Carrasco D., Padilla C., Leganés F., FernándezValiente E., Del Campo F.F. and Quesada A., 2002. Spatial and temporal heterogeneity in succession of cyanobacterial blooms in a Spanish reservoir. Ann. Limnol. - Int. J. Lim., 38, 173-183.

Sarnelle O., 1992. Nutrient enrichment and grazer effects on phytoplankton in lakes. Ecology, 73, 551-560.

Scheffer M., 1998. Ecology of shallow lakes, Kluwer Academic Publishers, Dordrecht.

Shapiro J., 1973. Blue-Green Algae: Why They Become Dominant. Science, 179, 382-384.

Shapiro J., 1997. The role of carbon dioxide in the initiation and maintenance of blue-green dominance in lakes. Freshw. Biol., 37, 307-323.

Søndergaard M. and Moss B., 1998. Impact of submerged macrophytes on phytoplankton in shallow freshwater lakes. In: Jeppesen E., Sondergaard M., Sondergaard M. and Christoffersen K. (eds.), The structuring role of submerged macrophytes in lakes, Springer, New York, 115-133.

Søndergaard M., Jensen J.P. and Jeppesen E., 2005. Seasonal response of nutrients to reduced phosphorus loading in 12 Danish lakes. Freshw. Biol., 50, 1605-1617.

Ter Braak C.J.F. and Smilauer P., 2002. CANOCO reference manual and user's guide to Canoco for Windows: software for canonical community ordination (version 4.5), Microcomputer Power, Ithaca.

Van Donk E. and Van De Bund W.J., 2002. Impact of submerged macrophytes including charophytes on phytoand zooplankton communities: allelopathy versus other mechanisms. Aquat. Bot., 72, 261-274.

Wetzel G.R. and Likens E.G., 1990. Limnological Analyses, Springer-Verlag, New York.

Willame R., Jurczak T., Iffly J.F., Kull T., Meriluoto J. and Hoffmann L., 2005. Distribution of hepatotoxic cyanobacterial blooms in Belgium and Luxembourg. Hydrobiologia, $551,99-117$. 